\title{
Work-Related Stress and Coping Profiles among Workers in Outer Garment Sector
}

\author{
Ozlem Koseoglu ORNEK ${ }^{1 *}$, Erdem Sevim ${ }^{2}$ \\ ${ }^{1}$ Department of Nursing, Faculty of Health Sciences, Turkey \\ ${ }^{2}$ Research Assistant, Department of Psychology Counseling and Guidance, Turkey
}

*Corresponding author: Ozlem Koseoglu ORNEK, Department of Nursing, Faculty of Health Sciences, Haciahmet Mahallesi, Pir Hüsamettin Sokak No 20, 34440 Beyoğlu, Istanbul, Turkey

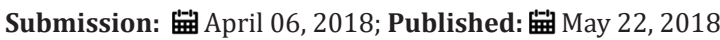

\begin{abstract}
Background: Garment sector has crucial working field in world. Work-related stress is common and alarming public health problem at workplace. It causes variety health and behavioural problems.

Aim: The objective of this study is to define level of job level, work-related stress' symptoms, social support and coping mechanisms of garment workers and to determine any related factors.

Method: This study is descriptive and cross-sectional. The study population comprised garment workers in the 16-65 age range. The data was collected by Assessment Form, The Brief Stress Coping Profile and Brief Job Stress Questionnaire.

Result: The study consisted of 719 workers. A clear majority of employees (54\%) (388) were in the 25-44 age group and 12.5\% (90) were in the 16-18 age group. The level of work-related stress was statistically higher among the workers who had chronic disease, low economic, education status and poor quality of sleep. Psychological and physical physiological reactions to stress were found higher among women workers and those with chronic disease. It also was seen that job stress scores had a meaningful relationship with "emotional expression involving others" $(r=.20)$ and "Avoidance and suppression" coping profile $(\mathrm{r}=.16 ; \mathrm{p}<.01)$.Psychological symptom scores were found to have a low level of meaningful relationship with "Seeking help for solution" ( $\mathrm{r}=-.08)$, "changing point of view" ( $\mathrm{r}=.13$ ) and "emotional expression involving others" coping profiles ( $\mathrm{r}=.21)$.
\end{abstract} stress.

Conclusion: Work-related stress causes many health and behavioral problems. Work related reasons and coping profiles have powerful effects on

Keywords: Stress reactions; Perceived work stressors; Coping skills; Occupational stress; Occupational health nurses

\section{Introduction}

Work-related stress is a very common problem among workers and its detrimental effects on human health is seen to be rapidly increasing compared to previous years [1]. Work-related stress occurs when the job demands and responsibility are not suited to the workers' ability or when the time allocated for the work is insufficient. Work-related stress causes many different health problems and unhealthy behaviours. These health problems vary but the most common ones are back pain, muscle pain, headache, stomach-ache, stomach bloating, constipation, high blood pressure, cardiac problems, depression, anxiety, tension, irritability, asthma. These problems would inevitably vary for each. However, with such negative developments the job quality and productivity decreases and sickness and absenteeism increase [2-9]. According to a report in Great Britain, 526,000 workers suffer from work related stress, depression or anxiety, 12.5 million working days lost due to workrelated stress, depression and anxiety in 2016/17. The main causes of work related stress were work load, lack of support, violence, threats and bullying [10]. Additionally, work-related stress was found to be main predictor of suicide among Korean workers [11]. Moreover, the effect of such stress varies across genders and age, as well. In particular, young workers are much more vulnerable than women due to their bio-psycho-sociological developmental periods which has an important influence on their choice of coping profiles and decision about their life in adulthood [12-15].

There could be many different factors which create workrelated stress but effective coping strategies and social support from co-workers, supervisors and family also have a crucial influence on dealing with stress $[16,17]$. Coping can be described as a process to manage internal and/or external sources by developing problemfocused coping mechanisms or emotion-focused coping strategies of psychological stress [18]. Coping strategies are commonly used efforts for solving problems in life [19]. Each of these strategies has different characteristics of cognitive procedure, behaviours and outcomes [20]. Problem-focused coping forthrightly address stressors while emotional-focused profiles alleviate any stress responses instead of attempting to resolve job stressors [21]. Socio- 
economic conditions, social support from co-workers, family and supervisors, knowledge and skills, intensity of work, long working hours, and role uncertainty have important effects on workers' job stress and coping profiles [22,23]. Coping profiles of workers also can be related to healthy life behaviors, perceived stress level, mental health problems and the success of controlling stress. Thus, effective coping strategies play an important role in controlling and preventing psychological and physical health problems (for example; cardiovascular diseases, musculoskeletal diseases, asthma, chronic obstructive pulmonary disease, irritable bowel syndrome) of workers [24-26]. Along with this, it is very crucial to be aware of work-related stress and its effective coping mechanism [21].

Recently, there has been growing awareness of the effects of the working conditions and their impact on psychological health but still there is not enough comprehensive research on workrelated stress, coping strategies and related factors. While work and working conditions get harder worldwide, it is important to control the causes of stress as much as developing of efficient coping skills for protection of workers' health and to protect them from diseases and unhealthy behaviours. Hence, there is a need for comprehensive descriptive cross-sectional studies for effective programs. Experts can use the result of the study as a guide in prolonging health protection and promotion programs. This study has two main aims;

A. To define level of job level, work-related stress' symptoms, social support and coping mechanism of workers,

B. To determine of related factors.

This study will seek for answers to the following questions:

A. What is the level of work-related stress, social support, physical and psychological reactions to work-related stress?

B. What kind of coping profiles have been used by the workers?

C. Which factors have influence on work-related stress, reactions of the stress and coping profiles of the workers?

\section{Method}

\section{Sample and settings}

This study is descriptive and cross-sectional. The study population comprised from six outer garment factories' workers in the 16-65 age range. The sample was selected by using a purposive sampling method from the factories have passed the laws and regulations on occupational health in Turkey as well as international inspections and controls. These factories export clothing abroad through a big centralized textile factory on the European side of Istanbul, Turkey. The data was collected in October, December and November 2016.

The study consisted of 792 garment workers of whom 20 did not fully complete the questionnaire, 13 were illiterate, 33 were absent during the data collection in the factories, and 7 of them refused to participate in the study. The final total number of workers participating in the research was 719 .

\section{Instruments}

The study was comprised of three instruments.

Descriptive workers assessment form: It consisted of Sociodemographic Characteristics (age, gender, education, birthplace, marital status, whether they child or not, perceptions of economic condition, classification of salary per month), health Characteristics (perceptions about their health, sleeping quality, any chronic disease under medical control or treatment, any disease or symptoms requiring a medical visit in the last 6 months, health status of family member), working Characteristics (working hours, occupation, working schedule, frequency and span of number of work breaks and duration and annual leave, self-perception of job performance).

The brief stress coping profile (BSCP): It consisted of 18 items rated on a 4-point scale (often, sometimes, seldom, or never). It is a self-rating scale for assessing workers' coping profile. It was developed by Kawashima \& Kanamaru [27]. It has 6 subscales which are; "Active solution", "Seeking help for solution", "Changing mood", "Changing a point of view", "Emotional expression involving others" and "Avoidance and suppression". Each of these subscales has 3 items and has a score range of 3-12 points. If a respondent shows a high score for a subscale, this means he/she frequently chooses that kind of coping method [28]. The Turkish version of the BSCP was used in this study and reliability and validity of the scale was done before conducting research. The reliability of the Turkish version of the BSCP Cronbach Alphavalues were 0.69, 0.71, $0.66,0.756,0.78$, and 0.77 respectively [29].

The Brief job stress questionnaire (BJSQ): The BJSQ was developed in Japan [30] and it consists of 57 items. The BJSQ cover job stress, physical and psychological stress reactions and social support. It self-assessed measurement. The higher score from subscale indicated high job stress, stress reactions or social support [31]. The Turkish version of the BJSQ was used in this study and reliability and validity of the scale was done before conducting research. The reliability of the Turkish version of the BJSQ Cronbach Alpha values was $0.66,0.81,0.82$ and 0.81 , respectively [29].

\section{Statistical Analysis}

Statistical analyses were conducted using the SPSS version 22 for Windows (SPSS, Inc, Chicago, IL, USA).

\section{Ethical Approval}

The Ethics Committee of Istanbul Medipol University approved the study procedure (approval no: 10840098-299) and permission was obtained from the factories. Then, it was given informed consent to the managers, the workers and to the young workers' family verbally and in written. Then, informed consent was obtained from all workers and additionally from parents of young workers prior to the administration of measurements. 


\section{Result}

Table 1: Descriptive characteristics of the workers and its relationship with mean values of the brief job stress questionnaire subscale scores (N:719).

\begin{tabular}{|c|c|c|c|c|c|c|c|c|c|c|c|c|c|c|c|}
\hline \multirow{2}{*}{\multicolumn{4}{|c|}{ Variables (N/\%) }} & \multicolumn{12}{|c|}{ The New Job Stress Questionnaire's Subscales } \\
\hline & & & & \multicolumn{6}{|c|}{$\begin{array}{l}\text { Psychological } \\
\text { Reactions }\end{array}$} & \multicolumn{3}{|c|}{ Physical Reactions } & \multicolumn{3}{|c|}{ Social Support } \\
\hline \multirow{3}{*}{ Gender } & Groups & $\mathrm{N}$ & $\%$ & $\overline{\mathrm{x}}$ & Sd & SEx & $\overline{\mathrm{x}}$ & Sd & SEx & $\overline{\mathrm{x}}$ & $\mathrm{Sd}$ & SEx & $\overline{\mathrm{x}}$ & $\mathrm{Sd}$ & Shx \\
\hline & Male & 347 & 48,3 & 43,45 & 5,05 & 27 & 33,62 & 7,78 & ,41 & 19,22 & 5,94 & ,31 & 31,53 & 5,51 & ,29 \\
\hline & Female & 372 & 51,7 & 43,85 & 5,61 & ,29 & 36,06 & 8,66 &, 44 & 21,26 & 5,59 & ,29 & 30,90 & 5,77 & ,29 \\
\hline \multirow{5}{*}{ Age } & Groups & $\mathrm{N}$ & $\%$ & $\overline{\mathrm{x}}$ & Sd & SEx & $\overline{\mathrm{x}}$ & Sd & SEx & $\overline{\mathrm{x}}$ & Sd & SEx & $\overline{\mathrm{x}}$ & Sd & SEx \\
\hline & $16-18$ & 90 & 12,5 & 42,6 & 5,04 & ,53 & 36,1 & 7,61 & 80 & 20,7 & 5,95 & ,62 & 34,1 & 5,55 & ,58 \\
\hline & $19-24$ & 142 & 19,7 & 43,2 & 5,21 & ,43 & 34,3 & 7,46 & ,62 & 20,2 & 5,29 & ,44 & 30,9 & 5,54 & ,46 \\
\hline & $25-44$ & 388 & 54,0 & 43,73 & 5,31 & ,26 & 34,6 & 8,64 &, 43 & 19,9 & 5,88 & ,29 & 30,9 & 5,60 & ,28 \\
\hline & $45-65$ & 99 & 13,8 & 44,7 & 5,76 &, 57 & 35,6 & 8,84 & ,88 & 21,1 & 6,36 & 63 & 29,82 & 5,26 &, 52 \\
\hline \multirow{5}{*}{$\begin{array}{l}\text { Education } \\
\text { Situations }\end{array}$} & Groups & $\mathrm{N}$ & $\%$ & $\overline{\mathrm{x}}$ & Sd & SEx & $\overline{\mathrm{x}}$ & $\mathrm{Sd}$ & SEx & $\overline{\mathrm{x}}$ & $\mathrm{Sd}$ & SEx & $\overline{\mathrm{x}}$ & Sd & SEx \\
\hline & Primary & 311 & 43,3 & 44,3 & 5,55 & 31 & 35,2 & 9,03 &, 51 & 20,0 & 6,02 & 34 & 30,5 & 5,49 & 31 \\
\hline & Secondary & 235 & 32,7 & 43,3 & 5,26 & 34 & 34,8 & 8,10 &, 52 & 20,6 & 5,83 & ,38 & 31,67 & 6,20 & ,40 \\
\hline & High school & 143 & 19,9 & 42,6 & 5,13 & ,43 & 34,0 & 7,66 & ,64 & 20,2 & 5,70 & ,47 & 31,9 & 5,30 & ,44 \\
\hline & University & 30 & 4,2 & 43,5 & 3,86 &, 70 & 35,7 & 5,16 & ,94 & 20,13 & 4,88 & 89 & 31,23 & 3,27 &, 59 \\
\hline \multirow{4}{*}{ Sleep Quality } & Groups & $\mathrm{N}$ & $\%$ & $\overline{\mathrm{x}}$ & Sd & SEx & $\overline{\mathrm{x}}$ & $\mathrm{Sd}$ & SEx & $\overline{\mathrm{x}}$ & $\mathrm{Sd}$ & SEx & $\overline{\mathrm{x}}$ & Sd & SEx \\
\hline & Bad & 155 & 21,6 & 45,1 & 5,05 & 40 & 38,6 & 8,96 &, 72 & 22,2 & 6,20 & 49 & 30,05 & 6,16 & 49 \\
\hline & Moderate & 247 & 34,4 & 43,70 & 5,10 & 32 & 36,2 & 7,55 &, 48 & 22,0 & 5,55 & 35 & 30,7 & 5,37 & 34 \\
\hline & Good & 317 & 44 & 42,8 & 5,51 & ,30 & 32,1 & 7,66 &, 43 & 17,9 & 5,01 & ,28 & 32,9 & 5,48 & ,30 \\
\hline \multirow{4}{*}{$\begin{array}{l}\text { General Health } \\
\text { Status }\end{array}$} & Groups & $\mathrm{N}$ & $\%$ & $\overline{\mathrm{x}}$ & $\mathrm{Sd}$ & SEx & $\overline{\mathrm{x}}$ & $\mathrm{Sd}$ & SEx & $\overline{\mathrm{x}}$ & $\mathrm{Sd}$ & SEx & $\overline{\mathrm{x}}$ & Sd & SEx \\
\hline & Good & 133 & 18,5 & 43,2 & 5,59 & 48 & 32,3 & 7,69 & ,66 & 18,1 & 5,57 & 48 & 32,1 & 5,69 & 49 \\
\hline & Moderate & 542 & 75,4 & 43,5 & 5,29 & 22 & 34,9 & 8,05 & 34 & 20,3 & 5,45 & 23 & 31,1 & 5,58 & ,23 \\
\hline & $\mathrm{Bad}$ & 44 & 6,1 & 45,7 & 5,05 & ,77 & 42,1 & 9,38 & 1,44 & 25,8 & 7,83 & 1,20 & 28,1 & 5,20 & 80 \\
\hline \multirow{3}{*}{ Chronic Disease } & Groups & $\mathrm{N}$ & $\%$ & $\overline{\mathrm{x}}$ & $\mathrm{Sd}$ & SEx & $\overline{\mathrm{x}}$ & $\mathrm{Sd}$ & SEx & $\overline{\mathrm{x}}$ & $\mathrm{Sd}$ & SEx & $\overline{\mathrm{x}}$ & $\mathrm{Sd}$ & SEx \\
\hline & Yes & 135 & 18,8 & 44,7 & 5,82 &, 50 & 37,2 & 9,16 &, 78 & 22,8 & 5,86 &, 50 & 30,3 & 5,92 &, 50 \\
\hline & No & 584 & 81,2 & 43,4 & 5,20 & ,21 & 34,3 & 8,04 & ,33 & 19,6 & 5,68 & ,23 & 31,4 & 5,57 & ,23 \\
\hline \multirow{4}{*}{$\begin{array}{l}\text { Month Income } \\
\text { (Dollars-\$) }\end{array}$} & Groups & $\mathrm{N}$ & $\%$ & $\overline{\mathrm{x}}$ & $\mathrm{Sd}$ & SEx & $\overline{\mathrm{x}}$ & $\mathrm{Sd}$ & SEx & $\overline{\mathrm{x}}$ & $\mathrm{Sd}$ & SEx & $\overline{\mathrm{x}}$ & $\mathrm{Sd}$ & SEx \\
\hline & $272,1-510,2$ & 590 & 82,1 & 43,8 & 5,47 & ,22 & 35,0 & 8,61 &, 35 & 20,5 & 5,83 & 24 & 30,9 & 5,78 & ,23 \\
\hline & $510,5-748,2$ & 79 & 11,0 & 42,6 & 4,83 &, 54 & 34,8 & 6,83 &, 76 & 20,4 & 5,84 & 65 & 31,6 & 4,83 &, 54 \\
\hline & $\begin{array}{l}748,6 \text { and } \\
\text { over }\end{array}$ & 50 & 7,0 & 42,4 & 4,25 & ,60 & 33,2 & 7,00 & ,99 & 19,1 & 6,08 & ,85 & 33,04 & 4,92 & 69 \\
\hline
\end{tabular}

Table 1 shows frequency and percentage values of the descriptive characteristics of the participants as well as standard error, standard deviation and mean values of the Brief Job Stress Questionnaire subscale scores pursuant to these demographic categories. The study consisted of 719 workers. A clear majority of employees (54\%) (388) were in the 25-44 age group and $12.5 \%$ (90) were in the $16-18$ age group. It has been found that $48 \%$ of these workers are male; $50.6 \%$ are married; $43.3 \%$ of them are primary school graduates; $86 \%$ are on day shift, while $14 \%$ of them work shifts, and $86 \%$ have been working more than 8 hours a day. $78.3 \%$ of workers stated that they started their working life when they were under 18 years old. A great majority of workers $(75.4 \%)$ stated their health status was "moderate" while only $18.5 \%$ declared "good" regarding their health status. However, approximately $19 \%$ were found to have a chronic disease and $60 \%$ had poor sleep quality. It is seen that $10 \%$ of employees work 'off the record' (uninsured). Over $82 \%$ of workers work for the minimum wage (510,5-748,2 American dollars = 800-1501 Turkish liras) and almost $26 \%$ stated their economic situation was "bad" (Table 1). 
Table 2: The determination of the brief job stress questionnaire and the brief stress coping profile's subscales scores vary across the groups; independent-samples t-test and one-way anova analyzes.

\begin{tabular}{|c|c|c|c|c|c|c|c|c|c|c|c|c|c|c|c|c|c|c|}
\hline & \multicolumn{3}{|c|}{ Gender } & \multicolumn{3}{|c|}{ Chronic Disease } & \multicolumn{3}{|c|}{ Working Hours } & \multicolumn{3}{|c|}{ Monthly Income } & \multicolumn{3}{|c|}{ Education Situation } & \multicolumn{3}{|c|}{ Sleep Quality } \\
\hline & \multicolumn{3}{|c|}{ 1.Male } & \multicolumn{3}{|c|}{ 1. Yes } & \multicolumn{3}{|c|}{1.8 hours } & \multicolumn{3}{|c|}{ 1. $272,1-510,2 \$$} & \multicolumn{3}{|c|}{ 1. Primary 2.Secondary } & \multicolumn{3}{|c|}{ 1. Bad } \\
\hline & \multirow{2}{*}{\multicolumn{3}{|c|}{ 2. Female }} & \multirow{2}{*}{\multicolumn{3}{|c|}{ 2. No }} & \multirow{2}{*}{\multicolumn{3}{|c|}{ 2. 12 hours or over }} & \multicolumn{3}{|c|}{$2.510,5-748,2 \$$} & \multicolumn{3}{|c|}{ 3. High school } & \multicolumn{3}{|c|}{ 2. Moderate } \\
\hline & & & & & & & & & & \multicolumn{3}{|c|}{ 3. $748,6 \$$ and over } & \multicolumn{3}{|c|}{ 4. University } & \multicolumn{3}{|c|}{ 3.Good } \\
\hline Variables & $\mathrm{t}$ & df & $\begin{array}{l}\text { Sig. } \\
\text { Dif. }\end{array}$ & $\mathrm{t}$ & df & Sig.Dif. & $\mathrm{t}$ & df & Sig.D & $\mathrm{F}$ & $\mathrm{p}$ & Sig. & $\mathrm{F}$ & $\mathrm{p}$ & Sig. Dif. & $\mathrm{F}$ & $\mathrm{p}$ & $\begin{array}{l}\text { Sig. } \\
\text { Dif. }\end{array}$ \\
\hline Job stress & $-1,01$ & 717 & ---- & $2,64^{* *}$ & 717 & $1>2$ & $-2,66^{* *}$ & 717 & $2>1$ & $3,32^{*}$ &, 04 & $\begin{array}{l}1>2 \\
1>3\end{array}$ & 3,925 & ,009 & $1>3$ & 6,76 & 001 & $1>3$ \\
\hline $\begin{array}{l}\text { Psychological } \\
\text { reactions }\end{array}$ & $-3,98^{* *}$ & 717 & $2>1$ & $3,62^{* *}$ & 717 & $1>2$ & $-2,76^{* *}$ & 717 & $2>1$ & 1,034 &, 36 & --- & 904 & ,439 & --- & 36,96 & ,000 & $\begin{array}{l}1>2 ; \\
1>3 ; \\
2>3\end{array}$ \\
\hline Physical reactions & $-4,47^{* *}$ & 717 & $2>1$ & $5,88^{* *}$ & 717 & $1>2$ & $-1,20$ & 717 & -- & 961 & ,383 & --- & 483 & 694 & --- & 44,19 & ,000 & $\begin{array}{l}1>3 ; \\
2>3\end{array}$ \\
\hline Social support & 1,48 & 717 & --- & $-2,82^{*}$ & 717 & $2>1$ & 10 & 717 & -- & $3,393^{*}$ & ,03 & $3>1$ & 1,880 & 132 & --- & 9,14 & 000 & $\begin{array}{l}3>1 ; \\
3>2\end{array}$ \\
\hline Active solution & $-1,03$ & 717 & ---- & $-1,48$ & 717 & --- & -0.35 & 717 & -- & $6,12^{* *}$ & 002 & $\begin{array}{l}3>1 \\
2>1\end{array}$ & 4,841 & ,002 & $3>1$ & 1,37 & ,254 & --- \\
\hline $\begin{array}{l}\text { Seeking help for } \\
\text { solution }\end{array}$ & $1,97^{*}$ & 717 & $1>2$ & $-1,19$ & 717 & --- &,- 11 & 717 & -- & 1,333 & 264 & --- & ,746 &, 525 & --- & 1,37 & ,255 & --- \\
\hline Changing mood & $-1,74$ & 717 & $-\ldots$ &,- 80 & 717 & --- & 19 & 717 & -- & ,815 & ,443 & --- & 1,961 & 119, & -- & 2,54 & ,080 & --- \\
\hline $\begin{array}{l}\text { Changing point } \\
\text { of view }\end{array}$ &,- 88 & 717 & --- &,- 69 & 717 & --- & $-1,24$ & 717 & -- & ,387 & ,679 & --- & 5,524 & ,001 & $\begin{array}{c}1>4 ; 2>4 \\
3>4\end{array}$ & 1,25 & ,286 & --- \\
\hline $\begin{array}{c}\text { Emotional } \\
\text { expression } \\
\text { involving others }\end{array}$ & $-1,71$ & 717 & --- & $4,35^{* *}$ & 717 & $1>2$ & ,34 & 717 & -- & $4,67^{*}$ & ,01 & $\begin{array}{l}1>3 \\
2>3\end{array}$ & 1,127 & 338 & --- & 2,80 & 061 & --- \\
\hline $\begin{array}{l}\text { Avoidance and } \\
\text { suppression }\end{array}$ & $-2,27^{*}$ & 717 & $2>1$ & $2,12^{*}$ & 717 & $1>2$ & $-2,20 *$ & 717 & $2>1$ & $9,96^{* *}$ & ,000 & $\begin{array}{l}1>3 \\
2>3\end{array}$ & 18,039 & 000 & $\begin{array}{c}1>2 ; \\
1>3 ; 1>4 ; 2>3\end{array}$ & 1,14 & ,321 & --- \\
\hline
\end{tabular}

T: Independent $t$ test df: Degrees of freedom Sig. Dif.: Significant differences * $=P \leq 0.05 * * P=\leq 0.01$.

Independent-samples T-test and One-Way Anova analyzes were conducted to determine whether the scores of the Brief Job Stress Questionnaire and the Brief Stress Coping Profile's subscales significantly vary across the groups. As shown in Table 2 , job stress scores different significantly by chronic diseases $(t=2,64)$, working hours $(\mathrm{t}=-2,66)$, monthly wages $(\mathrm{F}=3,32)$, education level $(\mathrm{F}=3,92)$ and sleep quality $(F=6,76)(p<.05)$. These results indicate that employees with chronic disease experience more stress at work; and those working $12+$ hours a day are more likely to feel stressed than employees working 8 hours a day. According to the complementary analyzes (Tamhane test) performed to determine which groups show significant differences by monthly wage, educational level and sleep quality variables, primary school graduates have higher job stress levels than high school graduates.

Workers who receive 800 to 1500 Turkish Liras per month have higher work-related stress than other wage groups. Furthermore, employees with poor sleep quality are seen to experience more stress than those with good sleep quality. Psychological reactions subscale scores indicate significant difference by gender $(\mathrm{t}=$ -3,98), chronic disease $(t=3.62)$, working hours $(-2,76)$ and sleep quality $(\mathrm{p}=.01)$. According to these results, women have higher psychological reactions and those with chronic diseases and working $12+$ hours a day have more psychological reactions. Employees with poor sleep quality were found to show more psychological reactions than those with moderate and good sleep quality and employees with moderate sleep quality had more psychological reactions than those with good quality sleep.

The physical reactions subscale scores show significant difference in favor of women $(\mathrm{t}=-4,47)$; and in favor of those with chronic disease $(t=5,88)$. However, those who have poor sleep quality show higher physical reactions than those with moderate sleep quality, in similar manner; workers with moderate sleep quality also show higher physical reactions than those with good sleep quality $(\mathrm{F}=44,19, \mathrm{p}<.01)$. According to the social support subscale scores, there is a significant difference in favor of those without chronic disease $(\mathrm{t}=-2,82, \mathrm{p}<.05)$. In addition to this, workers that receive 2.201+ Turkish Liras (748,6 American dollars) per month have higher social support scores than workers paid between 800-1501 Turkish Liras $(\mathrm{F}=3,39, \mathrm{p}<.05)$; there was a significant difference in social support scores in favor of the group with good sleep quality compared to the group with poor sleep quality; and in favor of the group with good sleep quality compared to the group with moderate sleep quality $(F=9,14, p<.01)$.

Employee scores of coping with stress indicate significant difference in favor of the group with 2.201+Turkish Liras monthly salary between the two groups consisting of employees with 800 1500 Turkish Liras and 2201 Turkish Liras monthly income and; in favor of the group that earns more between 800-1500 and 1501-2200 monthly income groups $(\mathrm{F}=6,12, \mathrm{p}<.01)$. In terms of 
education level, it is found that there is a significant difference in favor of the high school graduates between the groups comprised of high school graduates and the primary school graduates $(\mathrm{F}=$ $4,84, \mathrm{p}<.01)$.Seeking help for solution coping profile score showed significant difference in favor of men only by gender variable $(t=1,97)$. The changing mood coping profile scores do not show a significant difference with respect to subgroups of any variables $(p>05)$.

The changing mood profile scores show a significant difference only according to the educational status variable, and this difference is disadvantageous to the university graduates between the university graduate group and the other groups $(F=5,52$, p<.01)."Emotional expression involving others" coping profile scores indicate a significant difference in favor of those with chronic diseases $(t=4,35, \mathrm{p}<.01)$. According to the monthly wage variable, "Emotional expression involving others" scores show significant difference in favor of the group that earns less a month compared to the group with $2201+$ monthly wage and other groups $(F=4,67$, $\mathrm{p}<.05)$.

Finally, "avoidance and suppression" coping profile' scores indicate a significant difference in favor of women by gender $(\mathrm{t}=-$ 2.27); in favor of those with chronic diseases by chronic disease variable $(t=2,12)$; and in favor of those working over12 hours by working hours variable $(\mathrm{t}=-2,20)$. According to the monthly wage variable, "avoidance and suppression" scores indicate significant difference in favor of the group with 800-1500 Turkish liras monthly wage between 800-1500 Turkish liras and 1501-2200 Turkish liras monthly wage groups and; in favor of the group with
1501-2200Turkish liras monthly wage between 1501-2200Turkish liras and 2201+ monthly wage groups $(\mathrm{F}=9,97, \mathrm{p}<.01)$. According to educational level variable, "avoidance and suppression" scores show significant difference in favor of the group consisting of elementary school graduates compared to other groups; and in favor of the group of secondary school graduates compared to the group of high school graduates $(\mathrm{F}=18,04, \mathrm{p}<.01)$ (Table 2).

As shown in Table 3, Pearson's analysis, conducted whether there was a meaningful relationship between Brief Job Stress Questionnaire subscales and coping profiles of participants, revealed a low meaningful relationship amongst the subscales of the Brief Job Stress Questionnaire subscales. In addition, it was seen that job stress scores had a meaningful relationship with "Emotional expression involving others" $(r=.20)$ and "Avoidance and suppression" coping profiles $(\mathrm{r}=.16)(\mathrm{p}<.01)$.In other words, we can say that job stress increases when employees apply emotional expression involving others or Avoidance and suppression profiles in coping with work related stress. Psychological reactions scores were found to have a low level of meaningful relationship with "seeking help for solution" $(r=-.08)$, "changing a point of view" $(\mathrm{r}=.13)$ and "Emotional expression involving others" profiles( $\mathrm{r}=.21)$.

Findings between "seeking help for solution" profile and physical reactions s scores $(r=-.08)$, "changing a point of view" $(\mathrm{r}=.13)$ and "emotional expression involving others" profiles( $\mathrm{r}=.21)$ were found at a low of meaningful relationship. However, social support scores seem to be at a low level of meaningful relationship with other modes of coping except "active solution" (Table 3).

Table 3: The Correlation coefficients between the variables

\begin{tabular}{|c|c|c|c|c|c|c|c|c|c|c|}
\hline Variables & 1 & 2 & 3 & 4 & 5 & 6 & 7 & 8 & 9 & 10 \\
\hline 1. Job stress & 1 & & & & & & & & & \\
\hline 2. Psychological reactions & $.30^{* *}$ & 1 & & & & & & & & \\
\hline 3. Physical reactions & $.22 * *$ & $.51^{* *}$ & 1 & & & & & & & \\
\hline 4. Social support & $-.27^{* *}$ & $-.27^{* *}$ & $-.22 * *$ & 1 & & & & & & \\
\hline 5. Active solution & -0.06 & -0.07 & -0.05 & 0.055 & 1 & & & & & \\
\hline 6. Seeking help for solution & -0.003 & $-.11^{*}$ & $-.08^{*}$ & $.17^{* *}$ & $.25^{* *}$ & 1 & & & & \\
\hline 7. Changing mood & 0.07 & 0.01 & 0.15 & $.12^{* *}$ & $.27^{* *}$ & $.32^{* *}$ & 1 & & & \\
\hline 8. Changing point of view & 0.04 & $.13^{* *}$ & $.11^{*}$ & $.09 *$ & $.35^{* *}$ & $.30^{* *}$ & $.40^{* *}$ & 1 & & \\
\hline 9. Emotional expression involving others & $.20^{* *}$ & $.21^{* *}$ & $.14^{* *}$ & $-.09 *$ & -0.01 & $.09^{*}$ & $.18^{* *}$ & -0.05 & 1 & \\
\hline 10. Avoidance and suppression & $.16^{* *}$ & 0.07 & 0.06 & $-.10^{* *}$ & -0.03 & 0.03 & $.16^{* *}$ & $.11^{*}$ & $.27^{* *}$ & 1 \\
\hline
\end{tabular}

\section{Discussion}

The purpose of this study is to examine the level of work-related stress, physical and psychological reactions to the stress, social support, coping profiles of the garment workers and related factors. The results of the present study provide the primary evidence to identify physical and psychological health problems at workplaces. This study is one of the comprehensive researches in related fields among outer garment workers.
This study showed that long working hours, lack of sleep quality, having low economical situations and having chronical diseases increased perceived level of the work-related stress. Among coping profiles, Emotional expression and avoidance and suppression also have negative effects on level of work-related stress and its results. According to the present study, especially the use of emotional coping profile was higher among workers who had chronic disease and low-socio economic conditions. For example, the minimum wage in a month is between 330-376 dollars in Turkey. The outer 
garment workers who had this amount of salary were found to be much stressed than who earned more in the factory. This indicated that the minimum wage is insufficient for people to get on in life. The more workers get stressed the more they have unhealthy life. Because, work-related stress creates many health problems, such as; musculoskeletal disorders (back pain, neck pain...) [3,21], psychological health status (depression, anxiety...) and suicidal ideation $[4,11]$. There are variety related factors with work-related stress. According to the study of Nelson and Smith (2016) showed that, support at work, negative work characteristics and emotionalfocused coping styles of police officers were correlated with increase of depression [32].

Our findings indicated that psychological (feelingtense, irritable, restless, annoyed, weary, gloomy, depressed etc.) and physical reactions (headache, back pain, stiff shoulder or neck, eyestrain, constipation, stomach problems etc.) reactions were higher among workers who had Seeking help for solution, changing a point of view and Emotional expression involving others coping profiles in the factory. Generally, it is meaningful to say the factors that effects work-related stress level will also create physical and psychological health problems in the long term $[33,34]$. The findings in this study was supportive of that expression. Women and employees having bad sleep and having chronic disease in the study expressed higher physical and psychological health problems reactions. Women have more rolls roles and workload compare to men due to conditions of social life. They are trying to provide a balance between family and work that predicts of work-related stress [5].

Especially, perceived high levels of stress a different influence on men and women which effects of their approach problem in future life [15]. This study showed that, working 12 hours a day compared to 8hours/day was a crucial cause factor that increased psychological reactions. However, negative working conditions get worse in developing country. According to distribution by sector, almost $53 \%$ of employees work in services that included textile and garment industry in Turkey. This number just comprised formal registered workers. However, the unregistered employment rate is a growing problem throughout the garment sector. It is estimated that almost $70 \%$ of workforce in the garment sector is unregistered. Especially, Syrian workers are much more exploited due to not having legal work permits and lack of residency. That means that many workers are not able to get occupational health and safety services, at all. There is not certain information about these employees' working hours and the salary they get. Even though they work in much harder conditions without any social and personal rights for long hours. On the other hand, especially it is not possible to have a reliable countrywide data in Turkey since 2011 with Syrian migrants' movements to Turkey [34]. All these hard conditions are possible influential factors on increasing workrelated stress.

Perceived social support decreases work-related stress and its reactions' level. There is dynamic relationship between coping profiles and social support. According to the present study, the higher workers get social support the less they get stressed which also effects the way of coping profile. The findings of study in shoe manufacturing factory was consistent with our findings [33]. Except of active solution coping profile in the present study, seeking for social support or who had already higher social support from their family, supervisors or colloquies showed low association with other coping profiles. The workers who seek for help and to solve issues systematically mainly prefer active solution coping profile. However, Ineffective coping skills such as Avoidance and suppression of problems increases its adverse effects in time. It was found that there was a strong association between this coping profile and somatic symptoms, negative thought and depression [26]. Accordingly, this ineffective coping profile has been preferred more among the workers in this study who had just elementary school, chronic disease, long working time and women.

\section{Conclusion and Recommendations}

Work-related stress is alarming issue among workers. It causes many health and behavioral problems. Indirectly, it has strong negative influences on economy, too. There are many different reasons such as; long working hours, education level, gender, economic condition, having chronical disease, perceived social support and coping profiles have influential effects on work-related stress. However, effective coping profiles have key roles in preventing and protecting workers from the work-related stress. In this case, effective coping profiles should be discussed with the workers and employers and other related factors should be taken under control and promoted before work-related stress causes health problems and unhealthy life behaviors. The strength of this study is the application of a reliable large sample and valid measurements to the data. The results of the study are limited to the sample and the data was based on self-reporting and the probability of conferred report bias. Also, the study consisted of 6outer garment factories in Istanbul. Due to that, the results cannot be generalized to all garment workers in Turkey. Application of randomized controlled pre-post test studies in related area are recommended in order to evaluate of preventive work-related stress program and effective coping mechanism.

\section{References}

1. World Health Organization (2017) Occupational Health. WHO, Geneva, Switzerland.

2. Bergström G, Lohela Karlsson M, Kwak L, Bodin L, Jensen I, et al. (2017) Preventing sickness absenteeism among employees with common mental disorders or stress-related symptoms at work: Design of a cluster randomized controlled trial of a problem-solving based intervention versus care-as-usual conducted at the Occupational Health Services. BMC Public Health 17(1): 436.

3. Park JH, Park JH (2017) Association among work-related musculoskeletal disorders, job stress, and job attitude of occupational therapists. Occup Ther Heal Care 31(1): 34-43.

4. Oh H, Park H, Boo S (2017) Mental health status and its predictors among call center employees: a cross-sectional study. Nurs Health Sci 19(2): 228-236.

5. Loerbroks A, Ding H, Han W, Wang H, Wu JP (2017) No Title. Int Arch Occup Environ Heal 4(90): 349-356. 
6. Hoboubi N, Choobineh A, Kamari Ghanavati F, Keshavarzi S, Akba Hosseini A (2017) The Impact of Job Stress and Job Satisfaction on Workforce Productivity in an Iranian Petrochemical Industry. Saf Health Work 8(1): 67-71.

7. Mayerl H, Stolz E, Waxenegger A, Rásky É, Freidl W (2016) The Role of Personal and Job Resources in the Relationship between Psychosocial Job Demands, Mental Strain, and Health Problems. Front Psychol 17: 7.

8. Lee SJ, Lee JH, Gillen M, Krause N (2014) Job stress and work-related musculoskeletal symptoms among intensive care unit nurses: a comparison between job demand-control and effort-reward imbalance models. Am J Ind Med 57(2): 214-221.

9. Houtman I, Jettinghoff K (2007) Raising Awareness of Stress at Work in Developing Countries.

10. Shin YC, Lee D, Seol J, Lim SW (2017) What kind of stress is associated with depression, anxiety and suicidal ideation in Korean employees? J Korean Med Sci 32(5): 843-849.

11. Yu J (2017) Relationship between long working hours and metabolic syndrome among korean workers. Asian Nurs Res (Korean Soc Nurs Sci) 11(1): 36-41.

12. Bilsker D, Gilbert M, Myette TL, Stewart Patterson C (2005) Depression \& Work Function

13. Ornek OK, Esin MN (2017) Psychological health problems among adolescent workers and associated factors in istanbul, Turkey. Saf Health Work 20: 0-7.

14. Trolle N, Lund T, Winding TN, Labriola M (2017) Perceived stress among 20-21 year-olds and their future labour market participation - an eightyear follow-up study. BMC Public Health 17(1): 287.

15. Liu C, Wang L, Zhao Q (2015) Factors related to health-related quality of life among Chinese psychiatrists: occupational stress and psychological capital. BMC Health Serv Res 15(1): 20.

16. Peterson M, Wilson JF (2002) The Culture-Work-Health Model and Work Stress. Am J Health Behav 26(1): 16-24.

17. Lazarus RS, Folkman S (1984) Stress, Appraisal, and Coping. Paperback / softback, p. 456.

18. Gambetta Tessini K, Marino R, Morgan M, Anderson V (2016) Coping strategies and the salutogenic model in future oral health professionals BMC Med Educ 16(1): 224.

19. Nakagawa Y, Inoue A, Kawakami N, Tsuno K, Tomioka K, et al. (2014) Effect modification by coping strategies on the association of organizational justice with psychological distress in Japanese workers. J Occup Health 56(2): 111-123.

20. Takeda K, Watanabe Y (2017) Recognition of factors related to low back pain promotes behavior change among female nurses. J US China Med Sci 14: 8-18.
21. Cortina LM, Wasti SA (2005) Profiles in coping: responses to sexual harassment across persons, organizations, and cultures. J Appl Psychol 90(1): 182.

22. Inoue A, Kawakami N, Eguchi H, Tsutsumi A (2016) Buffering effect of workplace social capital on the association of job insecurity with psychological distress in Japanese employees: a cross-sectional study. J Occup Health 58(5): 460-469.

23. Doron J, Trouillet R, Maneveau A, Neveu D, Ninot G (2015) Coping profiles, perceived stress and health-related behaviors: a cluster analysis approach. Health Promot Int 30(1): 88-100.

24. Tabała K, Wrzesińska M, Stecz P, Kocur J (2016) Personality traits, level of anxiety and styles of coping with stress in people with asthma and chronic obstructive pulmonary disease-a comparative analysis. Psychiatr Pol 50(6): 1167-1180.

25. Sugawara N, Sato K, Takahashi I, Satake R, Fukuda S, et al. (2017) Depressive Symptoms and coping Behaviors among Individuals with Irritable Bowel Syndrome in Japan. Intern Med 56(5): 493-498.

26. Kageyama T, Kobayashi, Toshio Kawashima M, Kanamaru Y (2004) Development of the brief scales for coping profile (BSCP) for workers: basic information about its reliability and validity. Sangyo Eiseigaku Zasshi 46(4): 103-114.

27. Tomotsune Y, Sasahara S, Umeda T, Hayashi M, Usami K, et al. (2009) The association of sense of coherence and coping profile with stress among research park city workers in Japan. Ind Health 47(6): 664-672.

28. Ornek KO, Esin MN (2016) Effects of Workplace Mental Health Promotion Program on Work-related Stress and Coping Skills of Working Women. Istanbul University, Turkey.

29. Shimomitsu T, Haratani T, Nakamura K, Kawakami N, Hayashi T, et al. (2000) The final development of the Brief Job Stress Questionnaire mainly used for assessment of the individuals. Tokyo, Japan.

30. Sato Y, Miyake H, Theriault G (2009) Overtime work and stress response in a group of Japanese workers. Occup Med (Chic Ill) 59(1): 14-19.

31. Nelson KV, Smith AP (2016) Occupational stress, coping and mental health in Jamaican police officers. Occup Med (Chic Ill) 66(6): 488-491.

32. Minh KP (2014) Work related depression and associated factors in a shoe manufacturing factory in Haiphong City, Vietnam. Int J Occup Med Environ Health 27(6): 950-958.

33. Wada K, Sairenchi T, Haruyama Y, Taneichi H, Ishikawa Y, et al. (2013) Relationship between the onset of depression and stress response measured by the brief job stress questionnaire among japanese employees: A Cohort Study. PLoS One 8(2): e56319.

34. Turkey Country Study (2016) Turkey Country Study.
Creative Commons Attribution 4.0 International License

For possible submissions Click Here
Submit Article

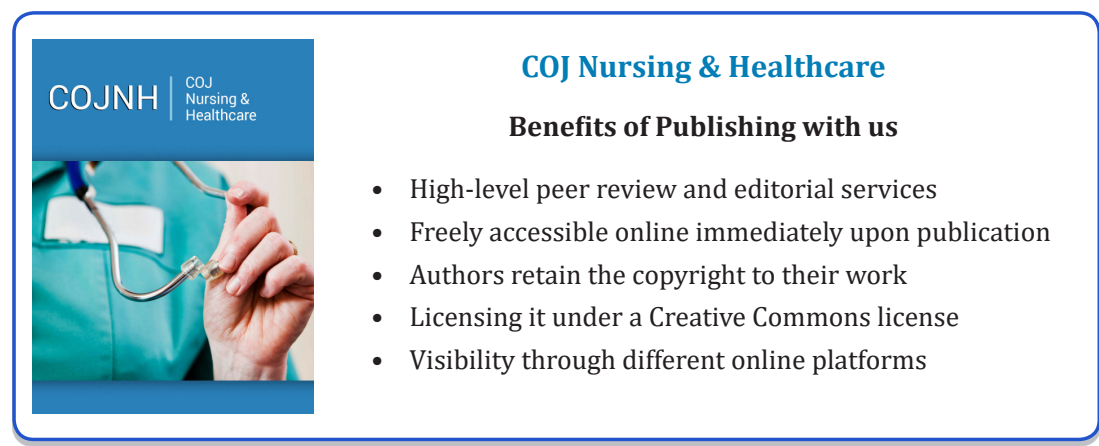

Volume-3 Issue-1

How to cite this article: Ozlem K O, Erdem S. Work-Related Stress and Coping Profiles among Workers in Outer Garment Sector. COJ Nurse Healthcare. 3(1). COJNH.000552.2018. DOI: 10.31031/COJNH.2018.03.000552 